\title{
Em busca do Encoberto: viagens à ilha encantada do Rei \\ Sebastião
}

\author{
Claudicélio Rodrigues da Silva ${ }^{1}$
}

\section{Nos passos do Encoberto}

\begin{abstract}
São ilhas afortunadas São terras sem ter lugar, Onde o Rei mora esperando. Mas, se vamos despertando Cala a voz e há só o mar.
\end{abstract}

(As ilhas afortunadas, Mensagem, Fernando Pessoa)

Há um povo no meio do mundo. Homens, mulheres e crianças cercados de água por todos os lados. O meio do mundo é uma ilha e se chama Lençóis, ${ }^{2}$ no Estado do Maranhão, região das reentrâncias maranhenses, a $300 \mathrm{~km}$ da capital, São Luís. Em meio a dunas e manguezais, cerca de cem casebres de madeira e palha escondem vários tesouros, materiais e imateriais. Os moradores, ou súditos, sabem quem é o verdadeiro dono dali e fazem questão de dizer isso a qualquer visitante: O rei Dom Sebastião, de Portugal,

1 Doutorando em Poética, Ciência da Literatura, Universidade Federal do Rio de Janeiro (UFRJ). Pesquisa de tese: "Sebastianismo no Maranhão: Poética oral e performance nutrindo imaginários”, bolsista CNPQ. E-mail: claudicelio@gmail.com. 2 Não confundir com os Lençóis Maranhenses. Esta ilha fica a oeste, enquanto o Parque Nacional dos Lençóis está à leste do estado e não é uma ilha. 
desaparecido na batalha de Alcácer-Quibir, no deserto marroquino do século XVI.

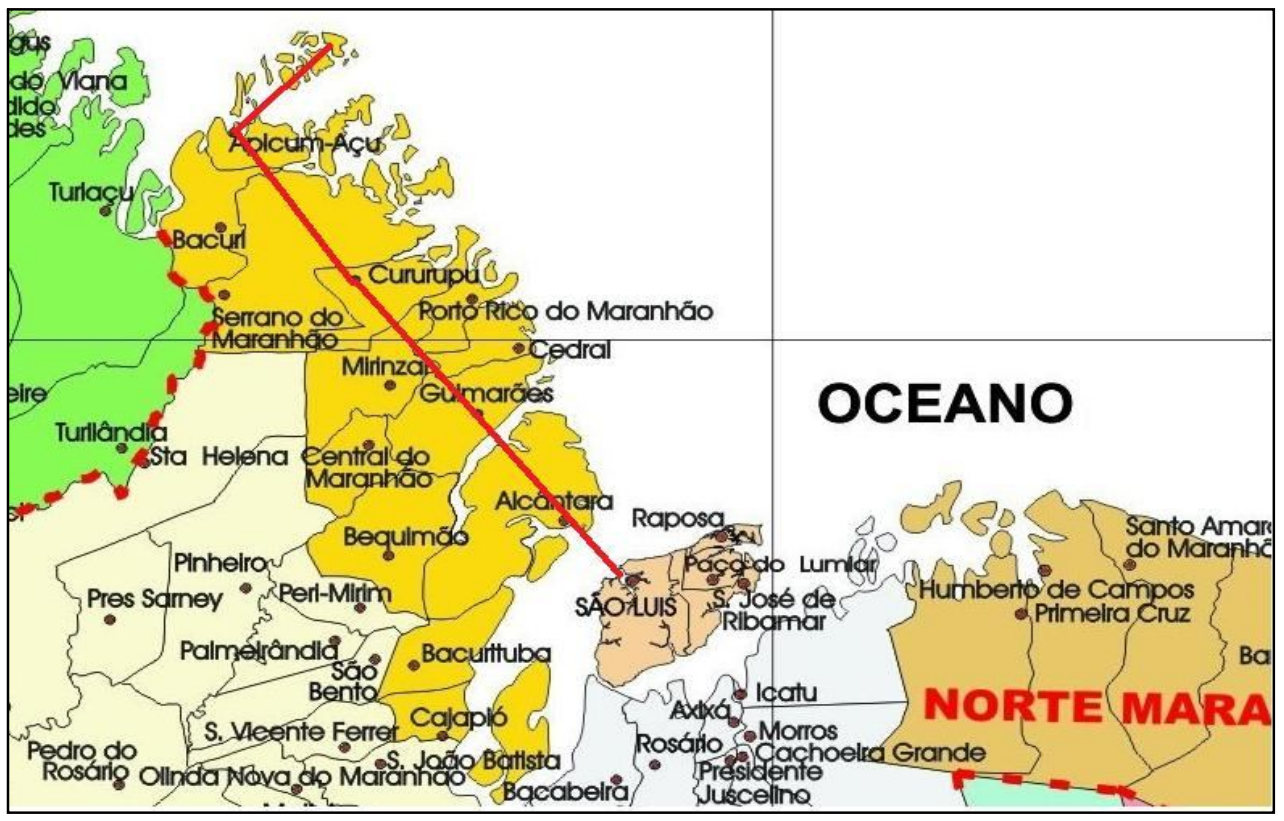

Figura 1. Detalhe do mapa do Maranhão

Chegar na ilha não é tão fácil. Depois de atravessar a furiosa baía de São Marcos, num ferry-boat, e percorrer quilômetros por estradas até chegar no porto, em Apicum-Açú (último município do continente), pega-se carona num barco de pesca que ainda leva de quatro a cinco horas para chegar ao paraíso escondido, bem próximo à linha do Equador. Detalhe: para embarcar, é necessário esperar a cheia da maré, uma das mais altas da costa brasileira. No desembarque, a visão das embarcações encalhadas no estuário em frente aos casebres e a exuberância da morraria ao lado (dunas, na linguagem dos moradores) de fato reforça a imagem de um lugar inóspito e mítico. Aquelas embarcações parecem dar um aviso: "Cuidado, você está entrando em território da ordem do desconhecido, do velado". Cercando a ilha, um manguezal exuberante serve de parede e proteção ao mesmo tempo em que é berçário de milhares de aves de cor real, a guará-vermelha. Reforça também a crença de que ali é morada dos encantados, ou seja, a Encantaria, palavra dos que cultuam o tambor de mina, um misto de 
culto afro e pajelança segundo o qual a natureza - água, matas, animais, terra - guarda mistérios e seres de um entre-mundo.

Até pouco tempo, a comunidade contava com um gerador de energia que funcionava das 19 às 22 horas. Alguns comerciantes tinham seu próprio gerador. Agora, com a implementação de uma central de energia mista solar e eólica (projeto da Universidade Federal do Maranhão (UFMA) e do Ministério das Minas e Energia os moradores terão energia 24 horas. São cerca de 18 ilhas que compõem a região, todas com manguezais fecundos, num bioma espetacular. À tardinha, as centenas de bandos de guarás-vermelhas

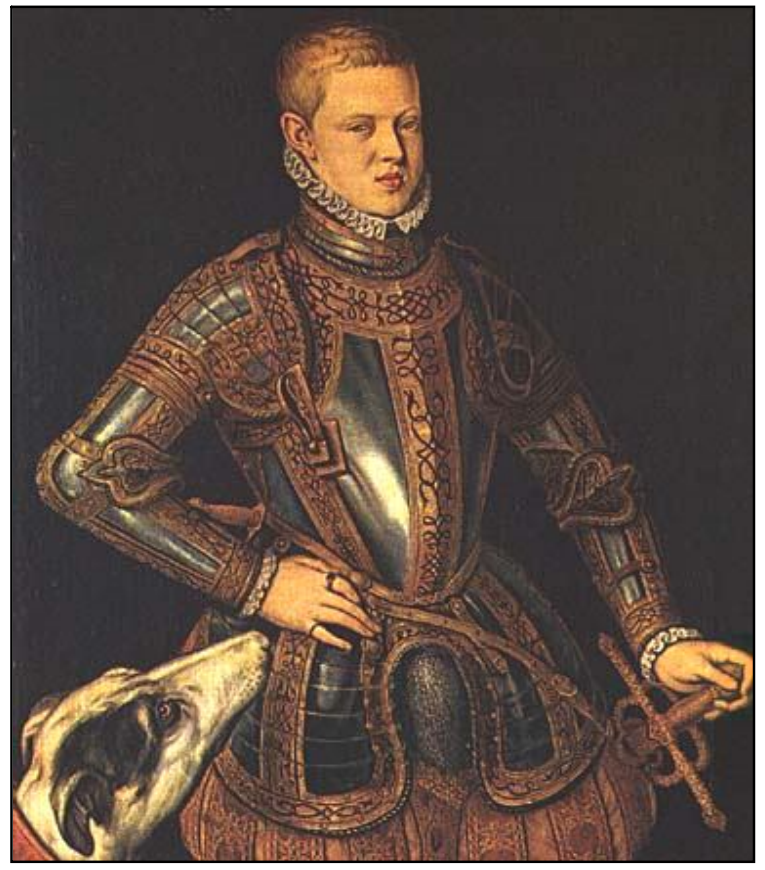

D. Sebastião, rei de Portugal (pintura a óleo atribuída a Cristóvão de Morais (séc. XVI) revoam e se empoleiram no manguezal do lado norte da ilha, em frente ao mar furioso. Nas dunas colhe-se murici, um fruto pequeno, amarelo e de sabor exótico. Dezenas de cajuais crescem ao sabor do vento, no topo de algumas dunas e servem de esconderijo para as cabras, vacas e crianças que aí brincam de esconde-esconde. Ao pé da morraria, é só cavar com as mãos que a água brota puríssima, pronta para matar a sede. É isso o que fazem as mulheres pela manhã e ao entardecer. Das 10 da manhã as 16 horas praticamente não se faz nada ao ar livre, devido a forte incidência de radiação solar pela proximidade da linha do Equador e a luminosidade da areia. Às vinte e duas horas, quando a luz do gerador é desligada, no céu explodem constelações enquanto na praia se observam pontos avermelhados, sinal de que a noite de trabalho está apenas começando para os pescadores. 


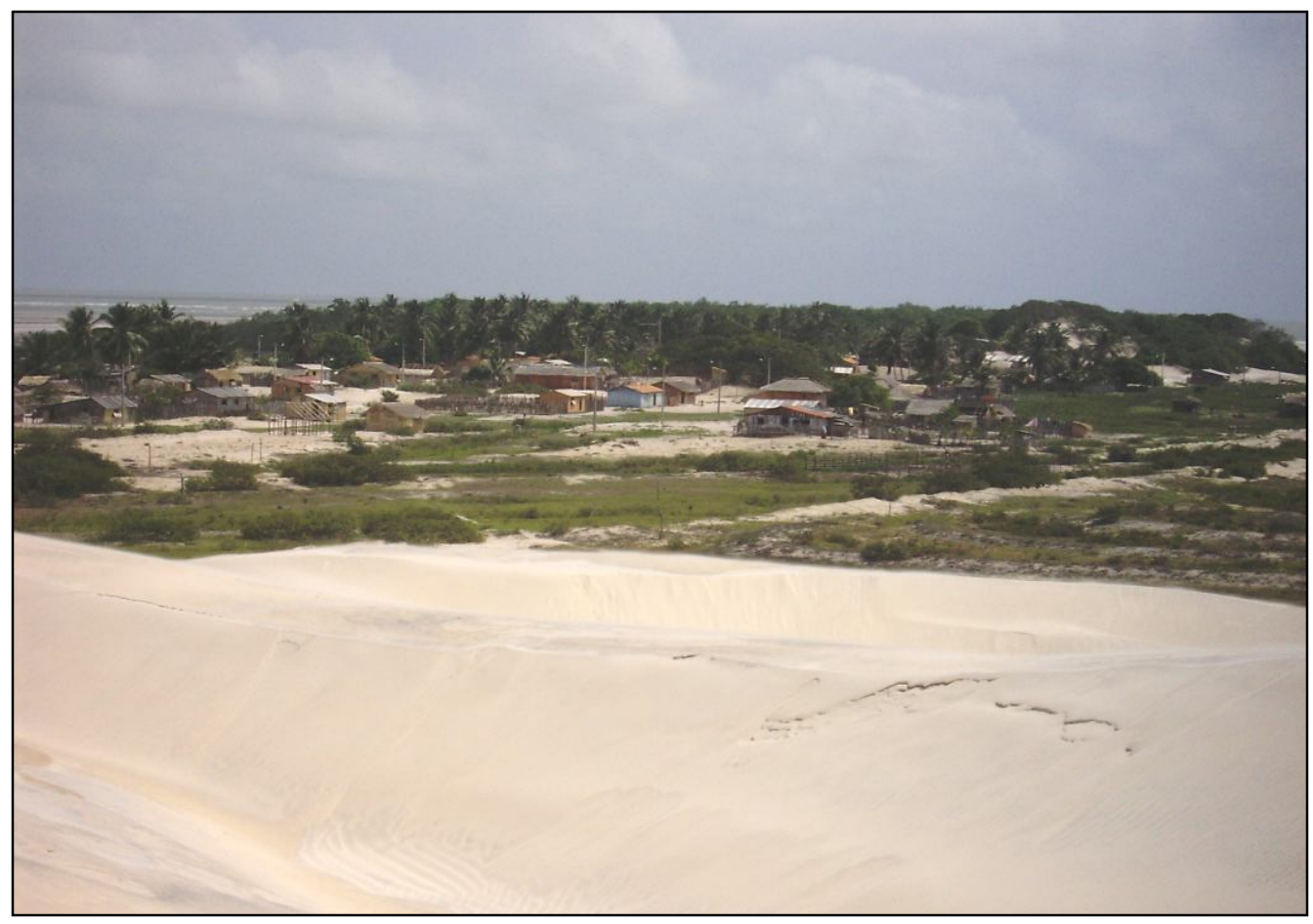

Figura 2. Ilha de Lençóis: povoado ao centro, manguezal e oceano no alto. No primeiro plano, as dunas que abrigam Dom Sebastião.

\section{A riqueza velada: um reino sob a morraria}

$\mathrm{Na}$ maioria das casas há pouca coisa, somente o suficiente para se dizer que casa é moradia. Então, onde está a riqueza desse tesouro? Alguns moradores dizem que embaixo da ilha há um outro mundo; outros dizem que está no mar; outros ainda afirmam que a riqueza mudou-se para outra ilha do arquipélago depois que o rei viu sua praia invadida por gente indesejada. É o Reino de Dom Sebastião, que guarda velada a maior riqueza que um povo pode ter: a memória, capaz de tecer lembranças nos fios coloridos de matéria imaginária e recuperar retalhos da história. Os detentores desse tesouro se intitulam "Filhos do Rei Sebastião”, pertencendo, pois, a uma alta estirpe de nobreza. Sem terem nada, têm tudo; e nada lhes falta quando lhes falta tudo. A Mnemósine, deusa da reminiscência, dotou e dota gerações com esse poder real. De pai para filho, de avô para neto, doutrinas, estórias e toadas são construídos, repassados e atualizados constantemente 
formando uma colcha de tecidos cujos fios poéticos dão vigor à crença na volta de Dom Sebastião.

Lá na ilha dos Lençóis veja o que me aconteceu Meia-noite na beira da praia Jarina me apareceu.

A filha do rei Dom Sebastião montada no seu cavalo com sua espada na mão.

(Lambada da Jarina, José Ribamar, 47 anos, habitante da ilha)

Se essa gente soubesse quão grande e poderoso é o seu tesouro... Parece que o tempo em Lençóis é como a areia levada pelo vento: nunca modela uma mesma duna, é sempre uma outra a duna que amanhece. Assim acontece com as narrativas dos encantados: nunca é a mesma a ser proferida porque a oralidade é movente por excelência. O passado remoto é refeito pela memória. Narrar é criar. No momento da fala, o presente nos dá o eterno, o vir-a-ser sendo constantemente. O tempo dos narradores da ilha não obedece outras regras que não sejam aquelas impostas pela Mnemósine.

Ele é um homem... um homem enorme, alto. Ele vem branco, ele é branco, já avistei ele num cavalo. Ele passa num cavalo, vem montado, lá perto do Grupo onde eu to, do colégio. Eu já vi... um cavalo, uma luar bonito... ele gosta de passar, passeia mais no verão, no mês de luar, setembro. Quando tão brincando também a Mina. Ele gosta de passear muito. Outro dia ele passou bem perto de minha casa, minhas filhas viram aqui. Um homem num cavalo, rei Sebastião.

(Simião, 75 anos, morador de Lençóis) ${ }^{3}$

3 Todos os cantos e relatos foram colhidos em janeiro de 2008, na Ilha de Lençóis. Outros cantos, doutrinas e narrativas estão vastamente registrados em arquivos sonoros e bibliográficos. Desde a primeira metade do século XX os moradores dessa ilha são alvo de pesquisas variadas por parte de historiadores, antropólogos, jornalistas, etc. Os moradores não só contam as lendas, como também tornam-se lenda, sendo alvo de estudos médicos, pelo fato de boa parte da população ser albina. 
Tal qual pegadas na areia, que permanecem por algum tempo informando e demarcando percurso, assim é a voz dos narradores: um mapa movente, nunca estático, cartografando itinerários dos encantados. São percursos que pregam peça para quem tentar seguilos. De repente, as pegadas são apagadas pelo vento ou pela água. De repente, pegadas se cruzam e confundem. Parecem dizer ao caminheiro desatento: "para chegares no teu destino, as pegadas estão em ti".

As pegadas estão nas vozes polifônicas dos que contam em verso e prosa as maravilhas do Rei Sebastião. Este universo se sustenta nas vozes dos patriarcas e matriarcas da ilha. Suas vozes misturam-se ao marulhar das ondas, à brisa do vento batendo nos coqueiros ou ao apito das embarcações, traduzindo-os. Aliás, eles nunca tomam para si a autoria das narrativas, cantos e doutrinas. Não são autores, mas performers do rei, tradutores da Encantaria, a morada mítica e mística.

(Telma canta uma doutrina para o Rei)

Sebastião quando baixa a coroa e faz as carnes da gente tremer Rei Sebastião, Rei Sebastião Entra em luta pra ganhar e vencer.

ENTREVISTADOR - Quem é que ensina essas doutrinas?

TELMA - Não, ele mesmo que traz em sonho, a gente dormindo. Aí vem. Quem é das coisas, enxerga. Eu enxergo. Eu não tenho medo. A primeira vez que eu vi ele, ele perguntou se eu tinha medo. Eu disse que não.

(Telma Maria, 33 anos, moradora de Lençóis) 
Tal qual um rapsodo na Grécia arcaica, porta-voz dos poetas e das Musas, assim são os narradores de Lençóis: costuradores de cantos. Os relatos fantásticos são permeados por música. Uma música remete a uma narrativa, ou vice-versa. Tudo é motivo para o mito. Às vozes dos narradores, se sobrepõe uma voz, a voz do rei velado, que pode vir do rolo do mar, como relatam as doutrinas cantadas, pode vir de um som do tambor misterioso ouvido bem ao fundo da morraria ou ainda do galope assombroso do cavalo branco do rei Sebastião que circunda a ilha certas noites.

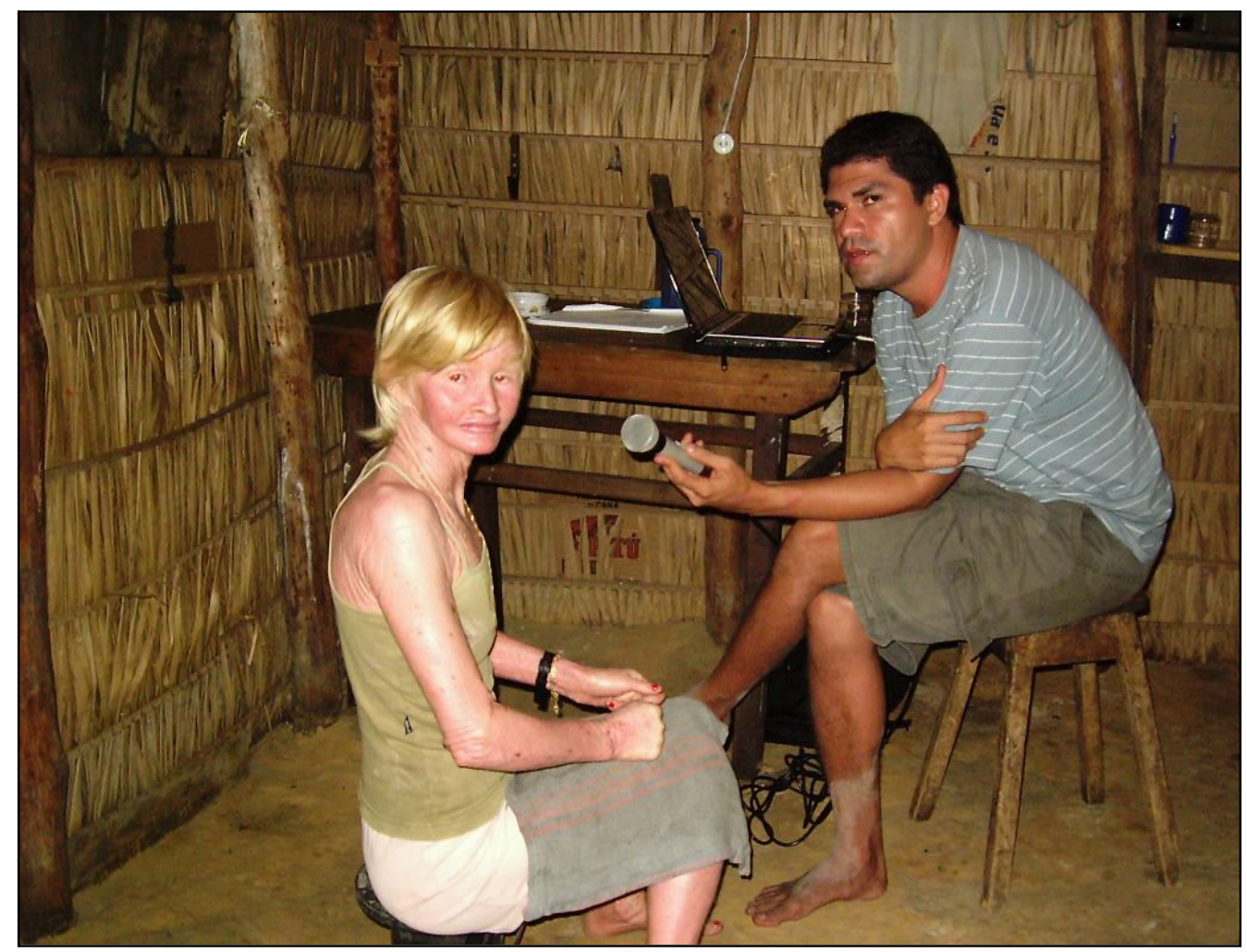

Figura 3. Telma em sua casa. Considera-se filha do Rei Sebastião. A ilha abriga muitos albinos, conhecidos como Filhos da Lua.

Tudo na ilha pode ser sinal desse devir. Só não vê quem não quer. E são muitos os que, com vista limpa, não enxergam, sobretudo os mais jovens, herdeiros que são desse tesouro. Mas o anúncio é claro, em canto e em narrativa: 
Hei, ê hei, Rei Sebastião

Hei, hei, Rei Sebastião

Quem desencantar Lençol

Vai abaixo o Maranhão.

(Maria Teresa, doutrina para o Rei Sebastião, Ilha de Lençóis)

TELMA - (...) Diz que Lençol vai ao fundo e Maranhão fica cidade. É verdade.

$\mathrm{E}-\mathrm{E}$ quando é que isso vai acontecer?

TELMA - Agora eu não sei quando é, mas vai... Que aqui fica São Luís. Aí aqui vai ao fundo e vai virar uma cidade.

Tudo leva a um devir. O tempo em que não haverá dois lados: dominante e dominados. Esse momento se apresenta e vários relatos. O fim de um mundo pela catástrofe anunciada parece não amedrontar os cantadores. Um mito engolindo outro. As figuras míticas são deglutidos: personagens históricas, a ilha, a cidade endeusada, os mitos do passado (escravidão, genocídio, desigualdade...) darão lugar à cidade mitopoética do Encoberto, espaço sagrado da liberdade. Essa São Luís que virá é a Gueluz, reino mítico do novamente Desejado.

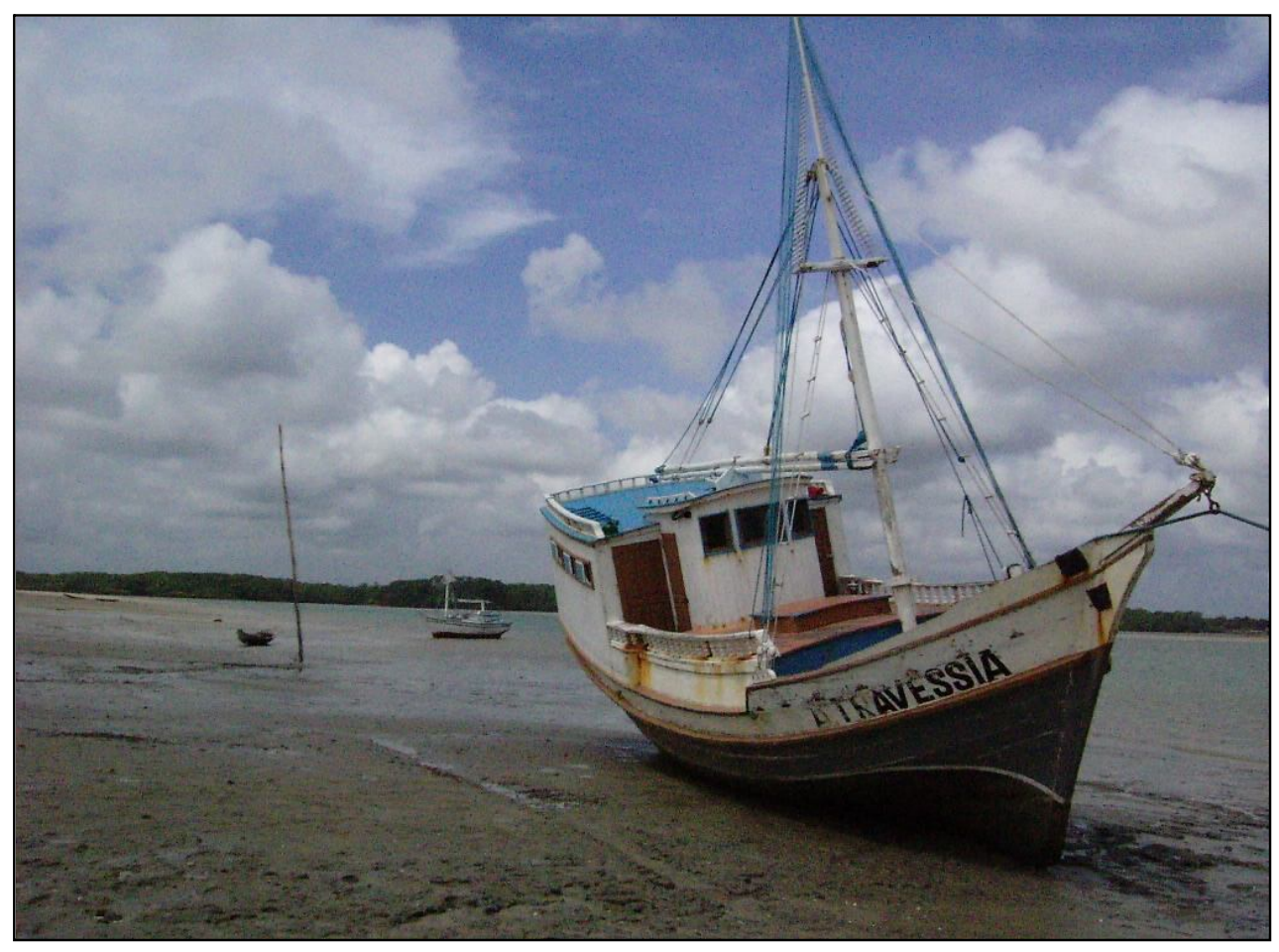

Figura 4. Barco "Travessia", que me levou à ilha. Aguarda a cheia da maré para a partida. 


\section{O apelo da escuta nos narradores da Ilha}

Os narradores da Ilha oferecem os seus segredos nos ritos, nas festas e sobretudo no seu cotidiano de pesca. A ilha se veste de cores e sonoridades. Sagrado e profano estão irmanados na espera do rei. Há solidão quando se tem deuses regendo o tempo, sempre sagrado? A condição insular do humano se faz presença aqui ao mesmo tempo em que aponta para a libertação. O discurso poético de pessoas tão simples e à margem da cidade parece dizer-nos que não somos ilha, solitariamente isolados. É preciso romper as amarras e grilhões que sufocam o homem. Não é um grilhão o medo diante do irracional, como se a racionalidade fosse o único suporte da Verdade? O convite está lançado. Para que ecloda o novo reino, divinamente humano, somos convocados a destruir os portos seguros que nos fazem ilha para nos realizarmos humanamente.

Para chegar à casa poética, um barco nos espera na grande travessia. Certeza é que a poiesis nos acolherá com o encanto de sempre. 